\title{
ELEMENTOS ARTÍSTICOS EN LA HISTORIA DE LA EDUCACIÓN: LAS PRÁCTICAS ARTÍSTICAS EN LOS ESPACIOS EDUCATIVOS
}

\author{
Artistic elements in the history of education: artistic practices in \\ educational settings
}

\section{Antoni Tort i Bardolet" y Eulàlia Collelldemont Pujadas ${ }^{\S}$}

Releyendo una entrevista a Jerome S. Bruner, con motivo de su fallecimiento el pasado junio de 2016, a la edad de 101 años, el psicólogo de Nueva York explicaba que su concepción de la psicología se fundamentaba en el querer saber acerca de nuestra capacidad para registrar el mundo, una capacidad no solo de percepción sino de procesamiento: «tenía la sensación de que esto era una de las fuentes de la libertad [de la humanidad], y esta es la razón, por ejemplo de porqué la literatura era tan importante, no solo estéticamente, sino también políticamente. Es la capacidad de soñar un abanico de posibilidades». ${ }^{1}$ Bruner nació ciego hasta que a los tres años una operación le permitió acabar con la oscuridad y empezar a ver el mundo. Este hecho influyó particularmente en su preocupación de cómo percibimos el mundo, de cómo se construye y de cómo las personas nos construimos en diálogo con nosotros mismos y en interacción con el mundo. Su referencia a la literatura, a la que dedicó muchas horas desde muy pequeño, tiene que ver no solo con una apertura al mundo (los ojos que se abren) desde una perspectiva mecánica, sino como una relación compleja que va más allá de la percepción física.

\footnotetext{
* Departament de Pedagogia. Facultat d'Educación, Ciències Humanes i Traducció. Universitat de Vic - Universitat Central de Catalunya. C/ Sagrada Família, 7. 08500 Vic. España. antoni.tort@uvic.cat $\S$ Departament de Pedagogia. Facultat d'Educación, Ciències Humanes i Traducció. Universitat de Vic - Universitat Central de Catalunya. C/ Sagrada Família, 7. 08500 Vic. España. eulalia@uvic.cat 1 «I turned in the direction of wanting to know about our capacity for registering the world. The world was there and we brought our input and processing of that input. I had the feeling this was one of the sources of [humankind's] freedom and liberty, and why literature was so important, not only aesthetically but also politically. It is the capacity to dream up a range of possibilities». Entrevista a Jerome Bruner en Kirsten Weir, «The centenarian psychologist», Bulletin of American Psychologist Association (APA)., Vol. 46, No. 5. May 2015: page 48. Acceso: http://www.apa.org/monitor/2015/05/ centenarian-bruner.aspx
}

Cómo citar este artículo: Tort i Bardolet, Antoni, y Collelldemont Pujadas, Eulàlia. «Elementos artísticos de la historia de la educación: las prácticas artísticas en los espacios educativos», Historia y Memoria de la Educación, 5 (2017): 9-14. 
Abordar la educación artística, el papel del arte, de las artes, la formación estética, en un monográfico de historia de educación nos sitúa en un panorama amplio, complejo y rico que analizaremos brevemente. Pero, en cualquier caso, cabe resaltar en primer lugar, al hilo de la anécdota bruneriana, que estamos ante un conjunto de temáticas que tienen que ver con un elemento, o conjunto de elementos, constitutivos de la condición humana. Las creaciones artísticas (música, literatura, artes plásticas...) son expresiones ricas y profundas que nos hablan de la relación del individuo con el mundo, en una reconstrucción constante de significados que enriquece el aprendizaje y el conocimiento humanos. La práctica del arte, la contemplación de la obra artística suponen formas de perfeccionamiento personal, acciones de performatividad que redundan en la profundización en la condición humana. Desde el mundo clásico, en Occidente y en Oriente, es un aspecto relevante que se puede rastrear en textos filosóficos y obras literarias.

En consecuencia, el ámbito del arte, como aspecto fundamental de la condición humana, lo es también, y en consecuencia, de la formación y la educación del individuo. A partir de este punto cabe plantearse el análisis de cómo a lo largo de la historia se ha considerado pedagógica y educativamente la experiencia estética. Un ámbito que podemos situar en el terreno de la recepción y de la percepción por parte de la persona individual, pero lógicamente y necesariamente en el contexto de una institución cultural y/o educativa. Al mismo tiempo y complementariamente, también nos planteamos cómo se ha construido histórica y educativamente, ${ }^{2}$ en el marco de procesos de enseñanza-aprendizaje, la posibilidad de aprender y de formarse en la experiencia artística en el sentido de permitir que «toda persona puede tener acceso a la producción artística puesto que la experiencia en este tipo particular de procesos de simbolización es importante para su desarrollo intelectual, afectivo y social». ${ }^{3}$

Así pues, la historia del pensamiento nos ofrece numerosas reflexiones acerca de la formación estética de la persona humana. Complemen-

\footnotetext{
${ }^{2}$ Herman Paul, Key Issues in Historical Theory (Oxon: Routledge, 2015).

${ }^{3}$ José María Barragán, «Educación artística: objeto de estudio, ámbitos disciplinares y tendencias» en Encuentros del arte con la antropología, la psicología y la pedagogía, eds. Alberto López Bargados, Fernando Hernández, José María Barragán (Manresa: Angle Editorial, 1997), 155.
} 
tariamente, la historia de la educación nos permite reconocer y analizar el lugar en el que la educación artística ha sido ubicada, ya sea en una educación general (el dibujo o la música en la escuela), o en una educación especializada (Escuelas de Artes y Oficios, Academias de Bellas Artes). Una ubicación que tiene que ver con la creación de sistemas institucionales a partir de los cuales se desarrollan las políticas culturales que una sociedad o un determinado sector hegemónico de la sociedad pone en marcha. Así pues, la historia de las instituciones situadas en el sistema educativo o en el sistema cultural (museos, centros culturales) nos permite entender también el papel de las artes y su centralidad o su marginalidad sociales, su prestigio o sus conflictos en los diferentes momentos y contextos históricos, así como su utilización para promocionar los valores de una sociedad en un momento concreto. ${ }^{4}$ Efectivamente, las obras artísticas, musicales y literarias contienen elementos para la comprensión de las prácticas políticas desarrolladas dado su potencial para conformar ideas e identidades y también para subvertirlas y desbaratarlas.

Las prácticas artísticas situadas en diferentes espacios educativos forman parte del recorrido que han tenido las ideas y las prácticas pedagógicas a lo largo del tiempo, y que se intensifican a partir de la modernidad en relación a la conceptualización del papel del arte y de las artes en la sociedad, en las indicaciones para la elaboración de materiales didácticos, en su inclusión en los currículos vía los aprendizajes artísticos o, incluso, en la recreación de ambientes educativos que promueven tanto el desarrollo personal como colectivo. No es de extrañar, por lo tanto, que el estudio de la historia de la educación artística tenga ya un bagaje y un recorrido considerables, los cuales nos permiten conocer las estrechas relaciones entre los postulados pedagógicos generales y las propuestas en el ámbito de la educación de las artes. La estética ha estado presente en la gran mayoría de aportaciones pedagógicas pensadas y desarrolladas desde la modernidad hasta ahora mismo. Pero también es reseñable la autonomía con la que la educación de las artes se ha ido articulando en relación a las ideas pedagógicas de su tiempo. Concomitancias e independencias pues, entre la educación y la educación artística con muchos

\footnotetext{
${ }^{4}$ Ver Arthur Edland, History of Art Education (New York: Columbia University. Teachers College Press, 1990). Existe una versión en español en Editorial Paidós.
} 
ejemplos a los que acudir: de Pestalozzi y Froebel a la Bauhaus, de Rudolph Steiner y las escuelas Waldorf a los escritos y actividades pedagógicas de Paul Klee o Joseph Beuys.

Como se puede constatar en la producción científica y en la actividad congresual y académica de los últimos años, en el área de la historia de la educación, en estos momentos, y gracias a la profundización en la historia cultural, a las aportaciones procedentes del campo de la etnografía, a las múltiples conexiones entre el mundo artístico y el mundo educativo, a la relevancia del «giro visual» en los estudios históricos, etc., ha crecido también la convergencia entre los análisis de carácter conceptual con aquellos que investigan las concreciones prácticas. Confluencia que en el ámbito de la historia de la educación estética y de la educación artística adquiere una importancia especial en la medida que posibilita adentrarse en las historias de la educación de los géneros artísticos sin renunciar, a pensar las ideas que acertadamente, o no, han guiado las prácticas educativas. Por lo tanto, los análisis abarcan una gran variedad de elementos, desde marcos conceptuales hasta la atención a los objetos, a los formatos y a los procedimientos. De las ideas filosóficas y pedagógicas a los objetos culturales y artísticos entendidos como «artefactos que trascienden los contextos de presencia/estado pero que son diferentes de los objetos en general en la medida en que incorporan formas de significación ampliadas». ${ }^{5}$

Por otra parte, el uso de las evidencias estéticas —novelas, filmes, carteles, fotografías, etc.- para el estudio de las acciones que han conformado la historia de la educación, sea integral, artística o incluso moral y política, nos abre un nuevo reto en el sentido de más posibilidades de acceso a imágenes de nuestra historia pasada y reciente. La inclusión de las expresiones artísticas y literarias como fuente documental para la historia de la educación ha experimentado un desarrollo considerable en estos últimos tiempos. Los textos escritos y la memoria oral se complementan con otros tipos de documentos que provienen de la imagen - fotografía o dibujo-, del cine, de la poesía o de la novela, y se convierten en elementos de gran valor para profundizar en la historia de la educación desde nuevos ángulos y para abordar mejor la complejidad de unas sociedades

\footnotetext{
${ }^{5}$ Anthony Giddens «El estructuralismo, el post-estructuralismo y la producción de la cultura», en La teoría social, hoy, eds. Anthony Giddens, Jonathan Turner (Madrid: Alianza Editorial, 1.998), 280.
} 
en la que las imágenes potencian «una realidad que se construye pluriforme, una característica de la cultura contemporánea que no depende de diseños u orientaciones centralizadas». ${ }^{6}$

En cualquier caso, estamos en un campo muy amplio, con múltiples ramificaciones y grandes confluencias, al que la historia de la educación está prestando una renovada atención en los últimos tiempos, como ya hemos señalado. En este contexto, la concreción de este número monográfico de Historia y Memoria de la Educación tiene su origen en la celebración del XVIII Coloquio de Historia de la Educación de la Sociedad Española de Historia de la Educación que se celebró en la Universidad de Vic (Barcelona) los días 8, 9 y 10 de julio de 2015. Las aportaciones y debates que se produjeron durante el Coloquio abrieron la puerta a que desde esta revista se planteara la idoneidad de dedicar un número monográfico a la educación artística. Los artículos que se presentan en este monográfico constituyen una muestra que integra diferentes parcelas del saber estético-artístico. Asimismo pretende dar cuenta de experiencias y planteamientos singulares que, a la vez, permiten una aproximación también de conjunto a tendencias y líneas de fuerza respecto de la relación entre el arte y la educación. El conjunto de textos es heterogéneo necesariamente por su procedencia y por el ámbito que abordan, del cine a la literatura, de la música a la reflexión filosófica sobre el arte. Pero a la vez nos permite subrayar la unidad y la transversalidad de las diferentes formas de creación artística.

Así pues, en el monográfico se aborda el papel del cine y de la fotografía en tanto que producto estético, a la vez que instrumento de descripción real y simbólica de un período social y educativo, como es el caso del cine en la transición política española o como lo son las fotografías que documentan la experiencia republicana de las Misiones Pedagógicas. La literatura infantil como instrumento para la educación en general o para la formación moral de los niños y las niñas aparece en diferentes trabajos de autores y autoras de la Península Ibérica y de Latinoamérica, ya sea a través de manuales escolares, cuentos infantiles o de las letras de canciones populares, o a través del teatro integrado en el currículum escolar. Literatura que también sirve para la formación docente. La reflexión sobre lo efímero y lo permanente, la obra artística como actividad de goce

\footnotetext{
${ }^{6}$ Gianni Vattimo, La sociedad transparente (Barcelona: Paidos/ICE UAB, 1990) 81.
} 
personal o como demostración de una crisis existencial. La música como vehículo de apertura al mundo para niños y niñas o la música como factor de distinción social. El arte como forma de aproximar a colectivos entre sí o el arte como elemento de que incrementa la brecha de conocimiento. Y, entre otros muchos aspectos, los valores educativos del arte en la obra de grandes pedagogos a lo largo de la historia de la educación. También, consideraciones metodológicas para investigar con imágenes y creaciones artísticas que plantean retos a los historiadores e historiadoras. En síntesis, un monográfico que pretende dar cuenta de la riqueza conceptual de la educación artística, del interés que tiene para la historia de la educación, y también del papel que el arte representará sin ninguna duda para la mejora y la transformación de nuestros sistemas educativos y para el enriquecimiento personal del conjunto de la población. 